\title{
Willingness to Communicate and its Relationship with Emotional Intelligence and Gender Differences
}

\author{
Leila Gholami, \\ (M.A. Student in TEFL) \\ Kharazmi University, Tehran Branch, English Department, Tehran, Iran \\ Email: I.gholami12@gmail.com
}

Keyword: Willingness to communicate, emotional intelligence, EFL learners

\begin{abstract}
As a matter of fact, contemporary universal education gives prominence on authentic communication as an ultimate goal of language learning. Language teaching and learning processes are among the most important and complex human endeavors which is the result of the complicated nature of human beings. Therefore, a successful language learner is the one who is capable of dealing with complexities of teaching-learning processes. Various recent learner-fronted teaching methodologies have underscored the notion of learner-initiated communication which is known as willingness to communicate (WTC). To date, various variables have been discovered by scholars to be influential in the satisfactory flow of communication among students in the language classrooms. Another variable analyzed in the present study is the potential relationship between learners' gender and WTC as well as their emotional intelligence (EQ-i). Therefore, the present study tries to investigate the possible go-togetherness between learners' willingness to communicate and their emotional intelligence. Two questionnaires of Bar-On's (1997) emotional quotient inventory and McCrosky's (1992) willingness to communicate scale were administered to a total of 100 academic EFL learners. After obtaining the raw data, the SPSS software (version17) was used to change the data into numerical interpretable forms. Correlation analysis revealed that there is positive correlation between learner's willingness to communicate and their emotional intelligence level. Furthermore, the findings characterized females as the outperforming group both in terms of emotional intelligence and willingness to communicate.
\end{abstract}

\section{INTRODUCTION}

There is no shadow of a doubt that communication is considered to be integral to the development of human relationships (Sallinen-Kuparinen, McCroskey, \& Richmond, 1991). Communication and language teaching are strongly related to each other. In fact, human beings acquire language through the medium of communication.

\subsection{Willingness to communicate}

Why do some students are inclined to communicate, whereas others avoid second language communication? According to MacIntyre and Doucette (2010, p. 162) "willingness to communicate can be perceived as a readiness to speak in the L2 at a particular time with a specific person, and as such, is the final psychological step to the initiation of L2 communication". Willingness to communicate is the most basic orientation toward communication. Almost anyone is likely to respond to a direct question, but many will not continue or initiate interaction. McCroskey and Baer (1985) defined willingness to communicate as a stable tendency towards the communication, given the choice. WTC is considered to be of paramount importance to the realm of language teaching, and it is basically because of its realization as the final intention to the initiation of the communication. The primacy of WTC lies in the fact that it partly arises from the role it plays in the interaction which undoubtedly leads to development. McCroskey and Bear (1985) regarded selfesteem, introversion, communication competence, communication apprehension, and cultural diversity as the determining factors which lead to WTC. Furthermore, MacIntyre and Charos 
(1996) added other key elements such as motivation, personality, and context to the above mentioned model.

\subsection{Emotional intelligence}

It is indisputable that affective variables play a predominant role in language learning. Numerous affective variables such as anxiety, inhibition, extroversion/introversion, self-esteem, motivation, attitude and learning style have been identified by scholars and educators in the field of education to be highly influential in learning/teaching process (Arnold \& Brown, 1999; Lightbown $\&$ Spada, 2006). There is a remarkable degree of consensus around the idea that emotional intelligence, not only as a defining feature plays a pivotal role in motivating individuals to learn but also it exerts a powerful influence over the learning procedure. It is self- evident that positive emotions facilitate language learning process, while negative emotions reduce learner's learning capacity (Meng \& Wang, 2006). More recently, the status quo of emotional intelligence has become the focal centre of interest of most of the scholars, investigators and educators. Numerous definitions have been given for EI. Skourdi, Rahimi, and Bagheri (2014) state that EI allows an individual to be motivated, to feel, to control impulse and accordingly to succeed in regular day-today living. Caine \& Caine (2002) puts more emphasis on the significance of the learners emotion for their meaningful learning. In fact People who are emotionally intelligent are able to understand and express themselves, interact well with others, and cope with the daily demands of life successfully (Bar On, 2000).

Generally speaking, second language learning is looked upon as a challenging task in a person's life. This is partly so because language learners are different not only in the way they deal with learning but also in terms of their feelings with regard to learning process. Goleman (1995) argued that success mostly depends on several intelligences and the control that we have over them. According tohis arguments, in addition to the intelligence (IQ), emotional intelligence (EQ) and social intelligences are also of paramount importance to lead one to success. Emotional intelligence is defined as having the capacity to track one's own and others' emotions and feelings, to differentiate among them, and to apply this to guide one's thinking and actions (Salovey and Mayer (1990). According to Salovey and Mayer (1990), an emotionally intelligent person has got characteristics that enable them to identify, use, understand and regulate emotions. For the first time, Bar-On (1997) coined the term emotional intelligence to quantify it. Based on his definition, EQ is a collection of capabilities, competencies, and non-cognitive skills that influence a person's capacity to be successful. Emotional intelligence impacts on interpersonal relationships (Bar-On, 2000). Bar-on (2000) identified five major scales each having some subscales that constitute emotional intelligence as follows:

(1) Intrapersonal: dealing with oneself, the capacity to know one's feelings.

(a) Emotional self-awareness (the capacity to be mindful of, perceive, and comprehend one's feelings).

(b) Assertiveness (the capacity to express one's emotions, convictions, considerations and to safeguard one's privilege).

(c) Self-respect (the capacity to be mindful of, comprehend, acknowledge, and admire oneself).

(d) Self-actualization (the capacity to acknowledge and achieve one's potential).

(e) Independence (the capacity to act independently in one's reasoning and activities and to be free from reliance).

(2) Interpersonal (overseeing associations with others).

(a) Empathy (the capacity to comprehend and admire others' emotions).

(b) Interpersonal-relationship (the capacity to create and maintain mutual understanding which are portrayed by intimacy and by giving and receiving).

(c) Social responsibility (the capacity to show oneself as an agreeable, contributing also useful individual from one's social group). 
3. Adaptability (the ability to adjust to change).

(a) Problem solving (the ability to appropriately solve the problems).

(b) Reality testing (the capacity to accept one's sentiments and musings by surveying the correspondence between what is subjectively experienced and what impartially exists).

(c) Flexibility (the capacity to change one's sentiments/musings to change).

(4) Stress management: controlling anxiety

(a) Stress tolerance (the capacity to deal with one's compelling feelings, unfavorable occasions, and unpleasant conditions by absolutely adapting to issues).

(b) Impulse control (the capacity to control one's feelings).

(5) General mood: the capacity to be hopeful and positive and also to appreciate life.

(a) Happiness (the capacity to feel fulfilled by life and to have a great time).

(b) Optimism (the capacity to look at the brighter side of life and keep up a positive demeanor despite issues).

\subsection{Gender differences in relation to willingness to communicate}

Sifting through many informative papers, it is undeniable that age and gender have profound impact on communication. It is also believed that gender may influence WTC. Gardner (1985) reports several studies that demonstrate more positive attitudes toward language learning among girls compared to boys. Wright (1999) also argues that girls have more positive attitudes towards language learning than boys. It is posited by authorities that girls reach maturity earlier than boys which helps them to be more dedicated towards schoolwork. Moreover, boys and girls developmental paths differ in adolescence. Thus, learner's interest in learning and their willingness to communicate (WTC) in an ongoing learning process is claimed in the current research to be influenced by emotional intelligence. It is ,therefore, stated that learners' emotional intelligence might play a part in this respect, and this is the crux of the matter in the current study. On the other hand, WTC is not a stable trait but varies according to age and gender. Despite the huge number of studies conducted in this realm of study, less has been explored regarding the relationship between WTC and gender in Iranian context. More specifically, the present study probes into the potential correlation between learners' emotional intelligence, their willingness to communicate as well as gender differences in WTC by posing the following research questions.

1. Is there any statistically significant relationship between Iranian EFL learners' willingness to communicate and their emotional intelligence?

2. Does gender have any effect on the relationship between emotional intelligence and willingness to communicate?

\section{LITERATURE REVIEW}

With the advent of an increasing tendency to communicate effectively, a growing need was emphasized to investigate the manifold aspects of WTC. It dates back to 1970s when Burgoon (as cited in Zarrinabadi \& Abdi, 2011, p. 206) mentioned the notion of "unwillingness to communicate" which she defined as "enduring and chronic tendency to avoid or devalue oral communication". Recently, however, the notion of WTC has attracted a surge of interest from researchers and language educators.

Peng (2007) argues that the concept of WTC should be ascribed to attempts by McCroskey and his colleagues. WTC was initially used with first language acquisition. Over the last two decades, second language acquisition (SLA) researchers such as MacIntyre, Clément, Dörnyei, and Noels (1998), and MacIntyre and Legatto (2011), have all emphasized the importance of WTC as a crucial component of modern language instruction. Kang (2005) defined this concept in this way "an individual's volitional inclination towards actively engaging in the act of communication in a specific situation, which can vary according to interlocutor(s), topic, and conversational context, among other potential situational variables" (p.291). Relationship between WTC and motivation has been studied by Peng (2007). Based on his findings motivation strongly predicted WTC. Leger and Storch (2009) made an attempt to gauge the role of learner's attitudes and perceptions of their own 
proficiency in enhancement of their WTC. As a result, positive correlation between participants' self-confidence and their WTC was concluded. Throughout the history, various strategies have been proposed by scholars to enhance WTC, among which Reinders and Wattana's (2011) investigation on the effectiveness of playing digital games on the enhancement of WTC can be mentioned. Birjandi and Amiri's (2011) investigation of the status of WTC in Persian children acquiring their first language led to the conclusion that WTC should be regarded as social characteristic and personality factor. Recently, Baghaei, Dourakhshan, and Salavati (2012), tried to probe the possible linkages between different scales of WTC and success in foreign language learning. Their study showed that two subscales of WTC i.e., the ones tapping learners' WTC in the school setting, mostly correlated with members' accomplishment in language learning. Though, the subscale of WTC with non-native speakers was not found to have a relationship with learners' success. In like way, Ghonsooly, Khajavy and Asadpour (2012) investigated Iranian non-English learners' WTC. The discoveries of the study, which was carried out on 158 academic learners, gave the analysts confirmation concerning the go-togetherness between WTC and factors like learners' selfconfidence and attitudes towards target community. Through this brief explanation, it is crystal clear that literature on WTC enjoys a great amount of depth and breadth. However, scant studies have been carried out to investigate the potential correlation between WTC and emotional intelligence across gender. Emotional intelligence have been posited to have very influential impact on learner's success in both academic (e.g. Matthews, Zeidner \& Roberts, 2002) and life settings (e.g. Murphy, 2006; Palmer, Donaldson \& Stough, 2002). Based on the findings of the present study emotional intelligence also plays a key role in encouraging and motivating learners to communicate and speak in the classroom context.

\section{METHOD}

This quantitative descriptive research is aimed at investigating the potential correlation between learners' emotional intelligence and their willingness to communicate across gender.

\subsection{Participants}

The participants of the study were 100 university learners majoring in TEFL, English Literature and English translation at Urmia University. Since gender is regarded as one of the variables in the current study, the total sample size represents participants of both genders (50males \& 50 females). Moreover, in terms of age, participants ranged between 20 and 30 years of age. It is noteworthy that based on the participants scores in the previous semester. The participants of the present study enjoyed an intermediate level of English proficiency.

\subsection{Instruments}

Two types of instruments will be applied to collect research data. The first one is Mccrosky's (1992) Willingness to Communicate Scale. This scale contains 20 items. The face validity of the instrument is strong, and results of extensive research indicate the predictive validity of the instrument. This scale gauges the respondent's tendency toward approaching or avoiding to initiate the communication. The reliability of the WTC scale is estimated to be .92 by McCroskey (1992). The second instrument is Bar-On's (1997) Emotional Quotient Inventory (EQ-i). The Emotional Quotient Inventory was used to measure the Emotional Intelligence of the participants. It includes 133 Likert-scale items. To carry out the present study, the domestically standardized version of this questionnaire was used (Samoui, 2005). The reduced version of the questionnaire containing 90 Likert-scale items was applied that was conceived suitable based on the purpose of the research.

\subsection{Procedure}

First of all, permission was obtained from the academic authorities of the Urmia University. Willingness to communicate questionnaire was distributed to the participants in the second half of the academic year. Participants were provided with the necessary instruction regarding the questionnaire's completion. Moreover, the purpose of administrating the questionnaire was explained. Participants were required to complete the part allocated for the demographic 
information such as age, gender, etc. Afterwards, Bar-On's (1997) EQ-I was distributed to the same participants.

\subsection{Data Analysis}

In order to analyze the collected data SPSS 17 (Statistical Package for the Social science) was run. Pearson's correlation analysis and the coefficient of each correlation were calculated to investigate any statistically significant relationship between Iranian EFL learners' Willingness to communicate and their Emotional Intelligence. Moreover, two independent samples T-tests were calculated to determine the difference between male and females' Willingness to Communicate and their Emotional Intelligence.

\section{RESULTS}

The first research question explored the relationship between learners' willingness to communicate and their emotional intelligence. In order to find the relationship, we used Pearson correlation coefficient. The result of correlation is depicted in Table 1.

Table 1. Correlation between WTC and EI

\begin{tabular}{cccc} 
Variables & N & $\begin{array}{c}\text { Pearson correlation } \\
\text { coeffiecient }\end{array}$ & Sig \\
\hline \hline WTC & 100 & 0.41 & 0.001 \\
EI & & & \\
\hline
\end{tabular}

As it is clear from the above table, there is a significant relationship between WTC and EI ( $<<0.05)$. Also the result of the correlation coefficient shows that there is a positive somehow strong relationship between these two variables. It means that learners' WTC increases with upward changes in their emotional intelligence.

The second research question explored the difference between male and female learners in the relationship between WTC and EI. For this purpose Independent sample t-test was used. The following tables will show the results.

Table 2. Independent Samples t-test on difference between WTC in Males and Females

\begin{tabular}{lccrcc} 
WTC & N & M & sd & T & Sig \\
& & & & & \\
\hline \hline Male & 50 & 68.35 & 12.43 & -3.86 & 0.002 \\
Female & 50 & 53.25 & 9.75 & & \\
\hline
\end{tabular}

As Table 2 represents, the amount of gained $p$-value was less than .05 , which is indicative of a significant difference between males and females in their WTC. Indeed, WTC mean in Males' group (68.35) was greater than the one in Females' group (53.25).

Also the researcher used independent sample t-test to explore the difference between Male and Female learners in EI. The following Table shows the result of independent sample t-test.

Table 3. Independent Samples t-test on difference between EI in Males and Females

\begin{tabular}{lccccc}
\hline WTC & N & M & SD & T & Sig \\
\hline \hline Male & 50 & 56.67 & 10.33 & -2.45 & 0.003 \\
Female & 50 & 45.62 & 15.43 & & \\
\hline
\end{tabular}


Based on the results of independent samples t-test depicted in the above table, a significant difference is shown between males and females in terms of their emotional intelligence. As it is clear from the above Table, The mean of Male learners' (56.67) is higher than the mean of female learners' (45.62).

\section{DISCUSSION AND CONCLUSION}

According to Gardner (1983), language learning and teaching is perceived as a highly intricate process. Such an intricacy arises from the fact that the internal mechanisms and social interactions that are involved in this process must be taken into account by teachers. Furthermore, Goleman (2001) states that since emotional intelligence serves as an internal mechanism and it fits with external environment, it can be of extraordinary help to somehow unravel such an intricacy. The aim of the present study was to find relationship between willingness to communicate and emotional intelligence among EFL learners across gender in Iranian context. In line with the previous theoretical studies on the role of WTC and EQ, the results of the present study indicated significant positive relationship between learners' willingness to communicate and emotional intelligence. The size of this correlation indicates that the higher the learners EQ, the more they are likely to initiate the communication. The second research question addressed the significant differences holding between males and females regarding their emotional intelligent level as well as their willingness to communicate. According to the results obtained from running independent samples T-tests, significant differences were reported between males and females in their both emotional intelligent level and willingness to communicate. Both EQ and WTC means in females' group were greater than the means in the males' group indicating that females' higher level of emotional intelligence may augment their tendency to initiate communication given the choice and consequently lead to more success in their development of language proficiency. As indicated by Bar-On (2000), EQ grows over the long term and can be enhanced through preparing, programming, and treatment. In light of the acquired results and by considering previous findings, we can defend creating courses for EFL learners concentrating on abilities connected with furthering learners' EQ and WTC. So enhancement of learners WTC and EQ must be among the preoccupations of policy makers dealing with learning| teaching. Students should be aware of the importance of emotional intelligence. Finally, since gender variable was indicated by the results of the present study to cause discrepancies between males' and females' in terms of both EQ and WTC, due attention on this issue especially in co-ed classes should be paid by instructors. Such an attention can influence the outcomes and expectations of the language instructors.

\section{Reference}

[1] Arnold, J., \& Brown, H. D. (1999). A map of the terrain. In J. Arnold (Ed.), Affect in language learning (pp.75-108). Cambridge: Cambridge University Press.

[2] Baghaei, P., Dourakhshan, A., \& Salavati, O. (2012). The relationship between willingness to communicate and success in learning English as a foreign language. MJAL, 4(2), 53-67.

[3] Bar-On, R. (1997). The emotional quotient inventory (EQ-i): A test of emotional intelligence. Toronto: Multi-Health Systems.

[4] Bar-On, R. (2000). Emotional and social intelligence. Insights from the emotional quotient inventory (EQ-I). In: Bar-On, R., Parker, J. D. (Eds.), The Handbook of Emotional Intelligence. Jossey-Bass, San Francisco. (pp. 363-388).

[5] Birjandi, P., \& Amiri, M. (2011). Willingness to communicate in the first language acquisition: A case study on Iranian 2-year old kids. European Journal of Social Sciences, 23(1), 44-55 
[6] Gardner, H. (1983). Frames of mind: The theory of multiple intelligences. New York, NY: Basic Books.

[7] Ghonsooly, B., Khajavy, G. H., \& Asadpour, S. F. (2012). Willingness to communicate in English among Iranian non-English major university students. Journal of Language and SocialPsychology, Retrieved from

http://jls.sagepub.com/content/early/2012/03/27/0261927X12438538

[8] Goleman, D. (1995). Emotional intelligence: Why it can matter more than IQ. New York, NY: Bantam Books.

[9] Goleman, D.(2001). An EI-Based theory of performance. In C. Cherniss, \& D. Goleman (Eds.), The emotionally intelligent workplace (pp. 27-44). San Francisco: Jossey Bass.

[10]Kang, S. J. (2005). Dynamic emergence of situational willingness to communicate in a second language. System, 33, 277-292. Léger, D. S., \& Storch, N. (2009). Learners' perceptions and attitudes: Implications for willingness to communicate in an L2 classroom. System, 37, 269285.

[11] MacIntyre, P. D., \& Charos, C. (1996). Personality, attitudes, and affect as predictors of second language communication. Journal of Language and Social Psychology, 15(1), 3e26.

[12] MacIntyre, P. D., \& Legatto, J. J. (2011). A dynamic system approach to willingness to communicate: Developing an idiodynamic method to capture rapidly changing affect. Applied Linguistics, 32, 149-171. doi:10.1093/applin/amq037

[13]Maclntyre, P. D., Clement, R., Dorneyei,Z., \& Noels, K. A. (199g). Conceptualizing willingness to communicate in a L2: A situational model of L2 confidence and affiliation. Modern Language Journal, 82, 545_562.

[14] MacIntyre, P.D., \& Doucette, J. (2010). Willingness to communicate and action control. System, 38(2),161-171.

[15] Matthews, G., Zeidner, M., \& Roberts, R. D. (2002). Emotional intelligence: Science \&myth. Cambridge, Massachusetts: MIT Press.

[16]Meng, X., \& Wang, Q. (2006). Psychological factors and teachers' language. US- China Foreign Language, 4(5), 70-73.

[17] McCroskey, J. (1992). Reliability and Validity of the Willingness to Communicate Scale.

[18]Communication Quarterly, 40(1), 16-25. http://dx.doi.org/10.1080/01463379209369817.

[19]McCroskey, P. D., \& Baer, J. E. (1985). Willingness to Communicate: the Construct and its Measurement. Paper presented at the annual convention of the Speech Communication Association, Denver, CO.

[20]Murphy, K. T. (2006). The relationship between emotional intelligence and satisfaction with life after controlling for self-esteem, depression, and locus of control among community college students. Unpublished PhD Dissertation. University of South Florida.

[21]Peng, J. (2007). Willingness to Communicate in an L2 and Integrative Motivation among Students in an Intensive English Language Program in China. TESOL, 2, 33-59.Palmer, B., Donaldson, C., \& Stough,C. (2002). Emotional intelligence and life satisfaction.

[22]Reinders, H., \& Wattana, S. (2011). Learn English or Die: The effects of digital games on interaction and willingness to communicate in a foreign language. Digital Culture \&Education, 3(1), 3-29.

[23] Sallinen-Kuparinen, A., McCroskey, J. C., \& Richmond, V. P. (1991). Willingness to communicate, communication apprehension, introversion, and self-reported communication competence: Finnish and American comparisons. Communication ResearchReports8,55-64. 
[24] Salovey, P., \& Mayer, J .D. (1990). Emotional Intelligence, Imagination, Cognition, and Personality, 9, 195-211.

[25] Samouei, R. (2005). Emotional intelligence test.Tehran: Sina Institute.

[26] Wright, M. (1999). Influences on learner attitudes towards foreign language and culture. Educational Research, 41, 197-208 